Increasing the Oxidative Stability of Poly(Dicyclopentadiene) Aerogels by Hydrogenation

J. M. Lenhardt, S. H. Kim, A. J. Nelson, P. Singhal, T. F. Baumann, J. H. Satcher

July 13,2012

ASC Macro Letters 
This document was prepared as an account of work sponsored by an agency of the United States government. Neither the United States government nor Lawrence Livermore National Security, LLC, nor any of their employees makes any warranty, expressed or implied, or assumes any legal liability or responsibility for the accuracy, completeness, or usefulness of any information, apparatus, product, or process disclosed, or represents that its use would not infringe privately owned rights. Reference herein to any specific commercial product, process, or service by trade name, trademark, manufacturer, or otherwise does not necessarily constitute or imply its endorsement, recommendation, or favoring by the United States government or Lawrence Livermore National Security, LLC. The views and opinions of authors expressed herein do not necessarily state or reflect those of the United States government or Lawrence Livermore National Security, LLC, and shall not be used for advertising or product endorsement purposes. 


\title{
INCREASING THE OXIDATIVE STABILITY OF POLY(DICYCLOPENTADIENE) AEROGELS BY HYDROGENA- TION
}

\author{
Jeremy M. Lenhardt ${ }^{\mathrm{a}, *}$, Sung Ho Kim ${ }^{\mathrm{a}}$, Art J. Nelson ${ }^{\mathrm{a}}$, Pooja Singhal ${ }^{\mathrm{a}}$, Theodore F. Baumann ${ }^{\mathrm{a}}$, Joe H. \\ Satcher, $\mathrm{Jr}^{\mathrm{a}, \mathrm{b}}$. \\ ${ }^{\mathrm{a}}$ Chemistry and Materials Science Directorate, Lawrence Livermore National Laboratory, Livermore, CA 94550 \\ ${ }^{b}$ Nanoscale Synthesis and Characterization Laboratory, Lawrence Livermore National Laboratory, Livermore, CA 94550 \\ Poly(dicyclopentadiene), Aerogel \\ Supporting Information Placeholder
}

\begin{abstract}
Ring opening metathesis polymerization (ROMP) of cycloolefins is a promising new route for the preparation of polymeric aerogels. The resulting unsaturation in the polymer backbone, however, makes these particular systems susceptible to oxidative degradation under ambient conditions. One method to increase the oxidative stability of these aerogels is to hydrogenate the material. In the present study, hydrogenation of poly(dicyclopentadiene) gels was achieved through thermolysis of paratoluenesulfonyl hydrazide in the presence of tripropylamine followed by solvent exchange and supercritical drying to form the hydrogenated aerogel (H- $p$ DCPD). Aerogels were prepared with varying densities and were characterized by FTIR-ATR, elemental analysis, BET, SEM, XPS, DSC and TGA. The oxidative stability of H- $p$ DCPD aerogels over $p$ DCPD was investigated through thermolysis in the presence of atmospheric oxygen. We report herein the synthesis and characterization of this new material.
\end{abstract}

There is increasing interest in the study of aerogels, a class of materials exhibiting low density, high porosity, high surface area and low thermal conductivity. ${ }^{1-5}$ Aerogels are typically synthesized by taking a wet gel precursor and subjecting the material to supercritical drying, this process negates the effects of capillary stresses that otherwise lead to gel destruction or shrinkage upon solvent removal. The result is a solid network wherein the liquid has been replaced with the ambient atmosphere, giving a low-density scaffold. Depending on their chemical composition, aerogels have found some applications as thermal $^{6}$ and acoustic insulators ${ }^{7}$, supercapacitors ${ }^{8}$, and potential chemical/energy storage platforms 9 . The uses of aerogels are as varied as their composition; the first aerogels being composed of silica ${ }^{10}$ followed soon after by the preparation of both transition metal ${ }^{11}$ and lanthanide oxides ${ }^{12}$. Though 'classic' aerogels are oxide-based; researchers have begun to successfully prepare organic aerogels such as resorcinolformaldehyde ${ }^{1}$, cellulose ${ }^{13}$, polyurethane ${ }^{14}$, and, of interest to us, poly(dicyclopentadiene) ${ }^{15}$.

Materials based on the polymerization of dicyclopentadiene (DCPD) to poly(dicyclopentadiene) ( $p$ DCPD) are gaining interest likely due to the ease of synthesis, cheap material cost, tolerance of polymerization conditions to oxygen and water, and the potential for polymer modification through the reaction of $p$ DCPD alkenes along the polymer backbone ${ }^{16}$. A combination of additional physical characteristics such as good physical and electrical properties have provided the impetus for its' use as a replacement material for reaction injection molding parts ${ }^{17}$. The popularity of $p$ DCPD and continued interest in aerogels has naturally led to the recent preparation $p$ DCPD aerogels ${ }^{15}$.

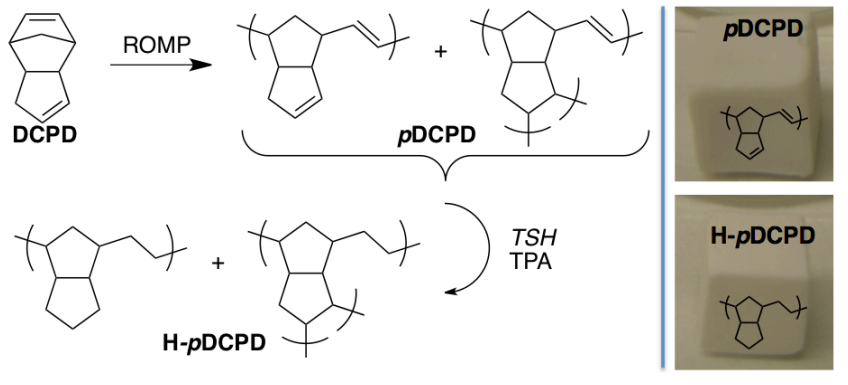

Figure 1. The preparation of poly(dicyclopentadiene) ( $p$ DCPD) gels through ring opening metathesis polymerization (ROMP). Hydrogenation of the gel using para-toluenesulfonyl hydrazide $(T S H)$ in the presence of tripropylamine (TPA) results in formation of hydrogenated poly(dicyclopentadiene) (H- $p$ DCPD). Supercritical drying leads to aerogels, shown to the right.

These $p$ DCPD aerogels are easily prepared first by ROMP of DCPD then supercritical $\mathrm{CO}_{2}$ drying of wet gels to give aerogels with nominal densities ranging from ca. 30 to $300 \mathrm{mg} \mathrm{mL}^{-}$ 1 . The aerogels are typically fibrous in nature with large surface areas $\left(>200 \mathrm{~m}^{2} \mathrm{~g}^{-1}\right)$ and low thermal conductivity (ca. 20 $\mathrm{mW} \mathrm{m}{ }^{-1} \mathrm{~K}^{-1}$ ) creating the possibility of its use as a novel insulation material.

The drawback of $p$ DCPD materials is that the high density of alkenes along the polymer backbone makes this material susceptible to oxidative damage. ${ }^{18}$ In many cases, the preparation of $p \mathrm{DCPD}$ polymers is coincident with the formation of small amounts of oxidation products along the polymer. In the case of solid $p \mathrm{DCPD}$ films, the oxidation process forms an oxide film that prevents further oxidation of the inner material ${ }^{19}$; this is likely not the case for an aerogel wherein the material porosity is larger than $90 \%$ and an outer, oxide film will not 
inhibit oxidation of the inner domains. To protect these aerogels from oxidative stress, we report herein that the hydrogenation of $p$ DCPD gels followed by supercritical drying to form hydrogenated H-pDCPD aerogels is a viable route to such an oxidatively stable aerogel material.
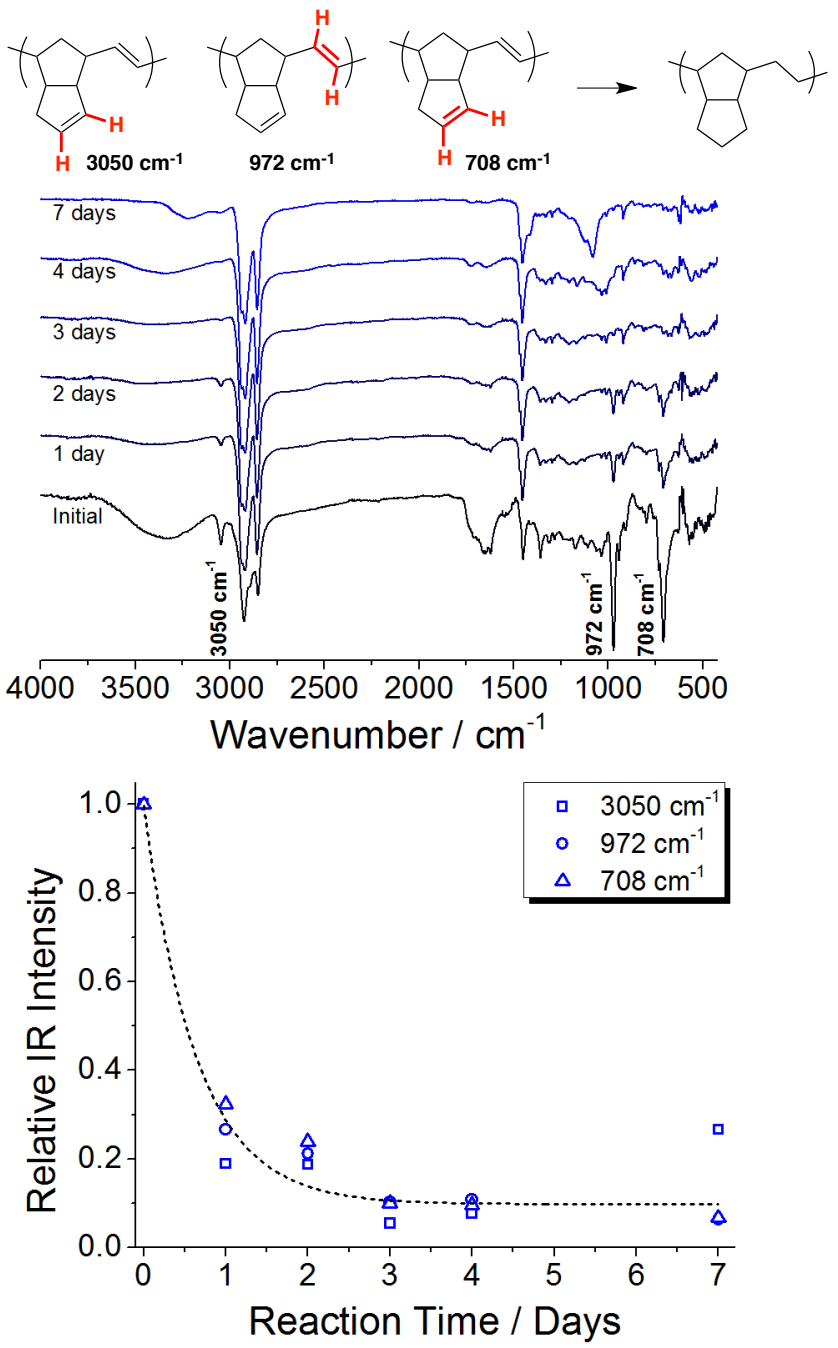

Figure 2. Hydrogenation of $p$ DCPD gels was monitored by FTIRATR, monitoring resonances at $3050 \mathrm{~cm}^{-1}, 972 \mathrm{~cm}^{-1}$ and $708 \mathrm{~cm}^{-1}$. Above, hydrogenation was conducted at $75{ }^{\circ} \mathrm{C}$ in the presence of 8 eq. TSH and 32 eq. TPA in 1,2-dichlorobenzene on $30 \mathrm{mg} \mathrm{mL}^{-1}$ $p$ DCPD gels for the annotated number of days. Attributed resonances are noted above the IR spectra. A plot of the relative IR intensity (bottom) versus reaction time shows consumption of the IR resonances after ca. 3 days of reaction. Fit provided to guide the eye.

To hydrogenate $p$ DCPD gels to H- $p$ DCPD, we used paratoluenesulfonyl hydrazide (TSH), a well-established hydrogenation agent that has found wide utility in polymer hydrogenation reactions ${ }^{20}$. For example, polyethylene can be prepared by hydrogenation of polybutadiene ${ }^{21}$, or further block copolymers of hydrogenated norbornene- $b$-polyethylene are also generated in this way $^{22}$. At elevated temperatures, TSH decomposes to form diimide and para-toluenesulfinic acid; in the presence of alkenes the diimide adds two hydrogen atoms across the double bond and nitrogen gas is released. Since we conducted hydrogenation reactions on solid $p$ DCPD gels, we found that the reaction required both longer reactions times and lower temperatures to (1) decrease the rate of $\mathrm{N}_{2}$ gas evo- lution that leads to trapped bubbles in the $p$ DCPD gel and/or degradation of the material and (2) allow the hydrazide to percolate the gel network to achieve full hydrogenation. Additionally, the use of tripropylamine was required to inhibit the reaction of $p$ DCPD alkenes with the formed sulfinic acid ${ }^{20}$.

We first determined the reaction temperature and duration required for hydrogenation of the $p$ DCPD gels. $30 \mathrm{mg} \mathrm{mL}^{-1}$ $p \mathrm{DCPD}$ gels [30- $p \mathrm{DCPD}$ ] were subjected to hydrogenation for varying times in the presence of 8 equivalents $T S H$ and 32 eq. TPA at $75{ }^{\circ} \mathrm{C}$ for up to 7 days of reaction in 1,2dichlorobenzene. The extent of reaction was followed using FTIR-ATR on supercritically dried aerogels by monitoring the intensity of IR absorbances at $3050 \mathrm{~cm}^{-1}\left(\mathrm{sp}^{2}=\mathrm{C}-\mathrm{H}\right), 972 \mathrm{~cm}^{-1}$ (trans double bond, $p$ DCPD main chain) and $708 \mathrm{~cm}^{-1}$ (cis cyclic double bond, $p$ DCPD unopened cyclopentene). ${ }^{23}$ An analysis of the relative IR intensity of hydrogenated H- $p$ DCPD aerogels (Figure 2) showed consumption of alkene absorbance in the IR spectra after ca. 3 days of reaction under these conditions, forming hydrogenated 30-H- $p$ DCPD.

The effect of TSH was next investigated, 30- $p$ DCPD gels (30 $\mathrm{mg} \mathrm{mL}{ }^{-1}$ ) were hydrogenated for 3 days at $75{ }^{\circ} \mathrm{C}$ wherein the number of equivalents (versus alkenes) of TSH was increased from 1 eq. to 10 eq. An analysis of the relative IR intensities of supercritically dried aerogels versus TSH showed a complete reaction when greater than 6 eq. of $T S H$ was used in the reaction (see SI, Figure S1).

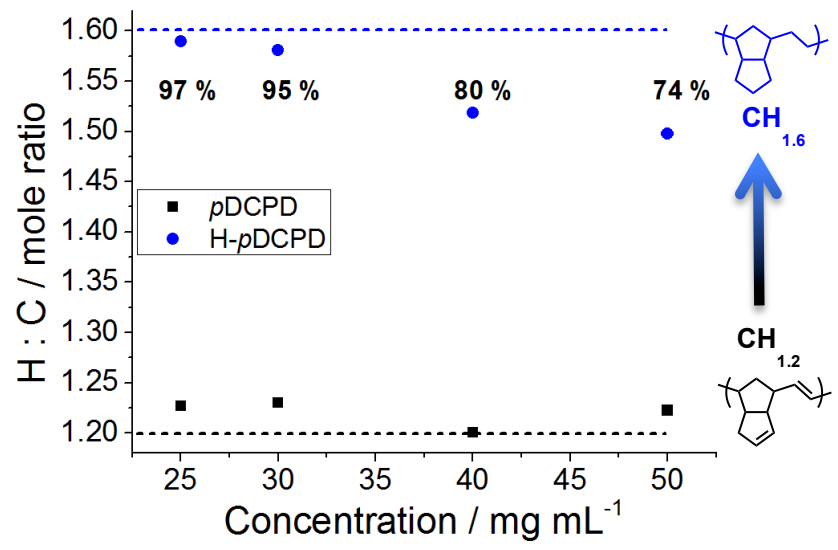

Figure 3. Elemental analysis of $p$ DCPD and H- $p$ DCPD aerogels of varying initial densities (as mixed, not directly measured here), here $100 \%$ hydrogenation leads to a $\mathrm{CH}_{1.6}$ material. The percentages indicate the degree of hydrogenation as calculated from the $\mathrm{CH}_{\mathrm{x}}$ balance.

To verify the formation of H- $p$ DCPD aerogels, we next hydrogenated a series of $p$ DCPD gels of varying initial density under our 'standard condition' $\left(75^{\circ} \mathrm{C}, 8\right.$ eq. TSH, 32 eq. TPA in 1,2-dichlorobenzene) and the atomic compositions were determined by elemental analysis (Figure 3). The extent of hydrogenation decreased with initial $p$ DCPD concentration, from $97 \%$ hydrogenation $(25-\mathrm{H}-p \mathrm{DCPD})$ to $74 \%$ hydrogenation (50-H- $p$ DCPD). This concentration effect is likely the result of the amount of DCPD incorporated into the $p$ DCPD gel prior to hydrogenation. For example, a series of $p$ DCPD gels were prepared in $1 \mathrm{~cm}^{3}$ glass molds, supercritically dried and weighed. The percent incorporation of DCPD into these gels was found to increase with increasing mixed density. A 25- $p$ DCPD aerogel was found to contain only ca. $12 \mathrm{mg}$ material, or $48 \%$ DCPD incorporation into the gel followed by 67 $\%, 75 \%$ and $80 \%$ for 30-, 40- and 50- $p$ DCPD aerogels re- 
spectively. The actual amount of DCPD in the $p$ DCPD gels prior to hydrogenation shows that the actual TSH content per alkene used in the hydrogenation reaction is largest at lower concentration (ca. 25- $p$ DCPD, $12 \mathrm{mg}$ DCPD; actual TSH $=16$ eq.) versus high-density $p D C P D$ precursors. A plot of the actual TSH equivalents versus the hydrogenation efficiencies (see SI, Figures S2) obtained from elemental analysis indicates that $>12$ equivalents of $T S H$ are required to obtain $>95 \% \mathrm{H}-$ $p$ DCPD aerogels under these reaction conditions.

The processing of wet gels into aerogels is commonly followed by shrinkage of the wet gel to an aerogel of increased density. ${ }^{24}$ We therefore monitored the densities of $p$ DCPD and $\mathrm{H}-p \mathrm{DCPD}$ aerogels, and, in addition, the morphological characteristics of the as-formed aerogels. The $p$ DCPD gels were first prepared in either cylindrical or square molds, then supercritically dried (SCD) with $\mathrm{CO}_{2}$. After SCD, the samples were weighed and measured to determine the aerogel density (Table 1). The resulting $p D C P D$ aerogels had densities ranging from $30 \mathrm{mg} \mathrm{mL}^{-1}$ (25- $p$ DCPD) to $109 \mathrm{mg} \mathrm{mL}^{-1}$ (50- $p$ DCPD), or shrinkage factors (final density $\div$ initial density) that increased from 1.2 to 2.2. By comparison, the densities of H- $p$ DCPD aerogels ranged from $48 \mathrm{mg} \mathrm{mL}^{-1}$ (25-H- $p$ DCPD) to $166 \mathrm{mg}$ $\mathrm{mL}^{-1}$ (50-H- $p$ DCPD), or shrinkage factors from 1.9 to 3.3 .

Table 1. Measured densities (d), pore volume (PV), pore diameter (PD) and aerogel surface area (SA) for $p$ DCPD and H- $p$ DCPD aerogels. Numbers beneath Sample ID indicate the mixed density $\left(\mathrm{mg} \mathrm{mL}^{-1}\right)$ of the wet gel prior to hydrogenation and supercritical drying.

\begin{tabular}{lllll}
\hline Sample ID & \multicolumn{1}{c}{$\boldsymbol{d} / \mathbf{m g ~ m L}^{-1}$} & $\mathbf{P V} / \mathbf{m L} \mathbf{g}^{-1}$ & $\mathbf{P D} / \mathbf{n m}$ & $\mathbf{S A} / \mathbf{~ m}^{2} \mathbf{g}^{-1}$ \\
\hline 25-pDCPD & 30 & 0.87 & 13.9 & 303 \\
H-pDCPD & 48 & 0.79 & 25.5 & 192 \\
30-pDCPD & 42 & 1.02 & 15.8 & 303 \\
H-pDCPD & 71 & 0.93 & 18.5 & 226 \\
40-pDCPD & 78 & 1.19 & 18.5 & 282 \\
H-pDCPD & 128 & 0.84 & 21.3 & 167 \\
50-pDCPD & 109 & 1.49 & 22.2 & 284 \\
H-pDCPD & 166 & 1.15 & 25.2 & 176 \\
\hline
\end{tabular}

The morphological characteristics of these aerogels were imaged using SEM, and we found that the fibrillar network characteristic of $p$ DCPD aerogels was conserved after hydrogenation. There were noticeable changes, however, in the hydrogenated aerogel surface areas, pore volumes and pore sizes versus $p$ DCPD analogues (Table 1). On average, H- $p$ DCPD aerogel surface areas decreased by ca. $35 \%$, pore size increased by ca. $15 \%$ and the pore volume decreased by ca. 20 $\%$.

The oxidative stability of H- $p$ DCPD aerogels was confirmed by thermal treatment of these materials in an oven in air (Figure 4). Samples were heated to $135{ }^{\circ} \mathrm{C}$ for 2 hours and the FTIR-ATR spectra were recorded to check for the formation of carbonyl (ca. $1700 \mathrm{~cm}^{-1}$ ) and/or hydroxyl (ca. $3400 \mathrm{~cm}^{-1}$ ) absorbances. The $p$ DCPD aerogels heated to this temperature and time underwent discoloration from white to brown/yellow coincident with formation of strong FTIR absorbances at both $3400 \mathrm{~cm}^{-1}$ and $1700 \mathrm{~cm}^{-1}$. In contrast, H- $p$ DCPD aerogels remained nearly white in color (slightly colored, 40- and $50-\mathrm{H}-$ $p$ DCPD due to incomplete hydrogenation) and no new FTIRATR absorbances were observed to indicate formation of any oxygen-containing moieties.
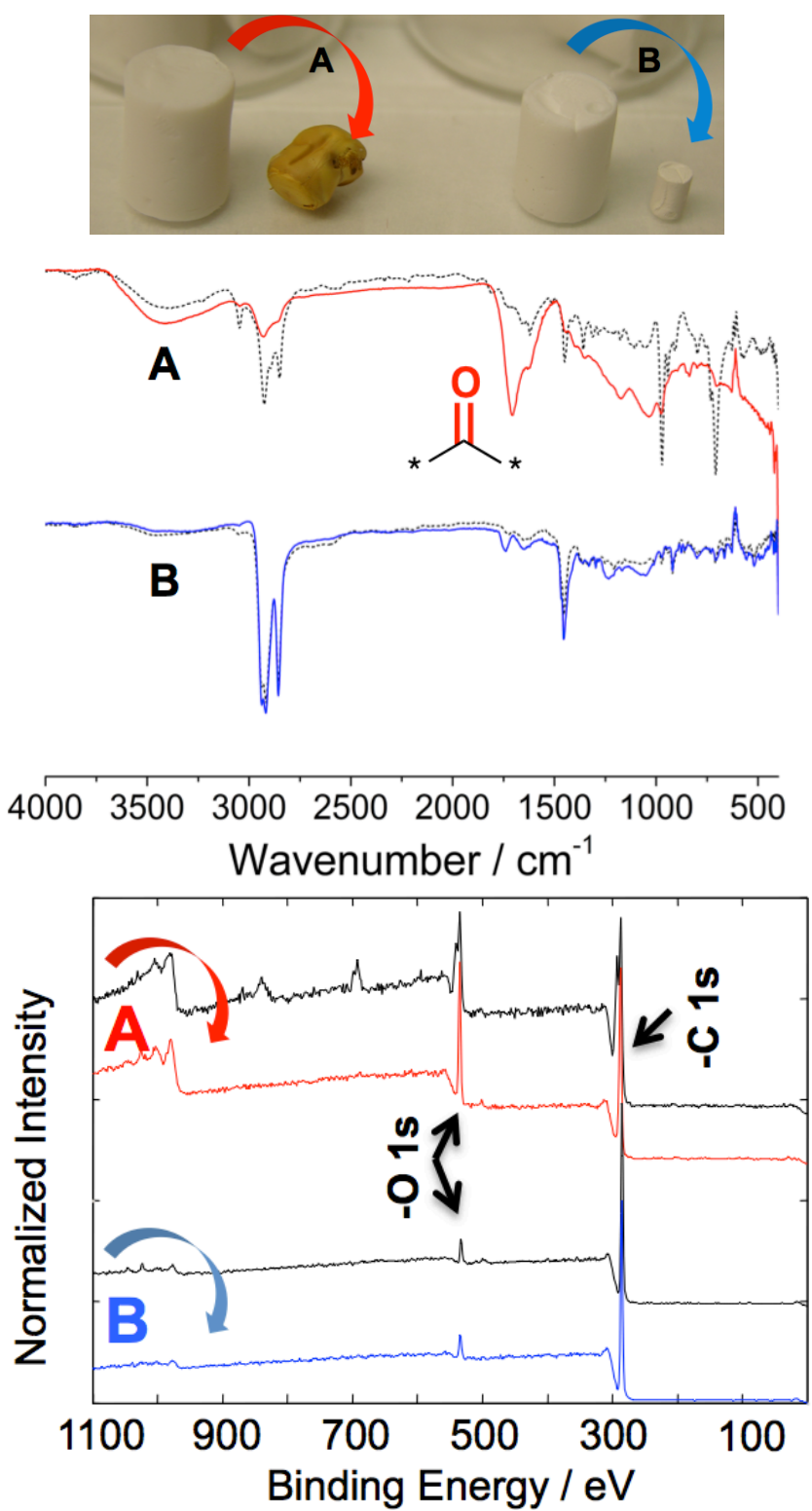

Figure 4. Images (top) of 25- $p$ DCPD (A) and 25-H- $p$ DCPD (B) aerogels before and after thermolysis at $135^{\circ} \mathrm{C}$ for 2 hours in air. FTIR-ATR spectra (middle) show formation of carbonyl absorbances at $1700 \mathrm{~cm}^{-1}$ for thermalized 25- $p$ DCPD while the spectrum of 25-H- $p$ DCPD remains unchanged. XPS (bottom) spectra before and after thermolysis of aerogels shows an increase in oxygen content for thermalized 25- $p$ DCPD while that of $25-\mathrm{H}-p$ DCPD remains unchanged.

One thermalized sample set was further analyzed using x-ray photoelectron spectroscopy (XPS, Figure 4). The XPS spectrum of $25-p D C P D$ showed $79.2 \%$ carbon and $16.3 \%$ oxygen with slight contributions from fluorine $(4.3 \%)$ and chlorine $(<1 \%)$. Thermolysis of this aerogel $\left(135{ }^{\circ} \mathrm{C}, 2\right.$ hours in air) was followed by an increase in the total oxygen content in the 
aerogel to $20.5 \%$. The XPS spectrum of $25-\mathrm{H}-p$ DCPD aerogel showed virtually no increase in oxygen content after thermolysis. The hydrogenated aerogel initially consisted of $93.9 \%$ carbon, $4.6 \%$ oxygen and small contributions (ca. $1.5 \%$ ) from nitrogen, chloride, sodium and zinc (unknown contaminants). Thermal treatment $\left(135{ }^{\circ} \mathrm{C}, 2\right.$ hours) led to an aerogel composition of $95.3 \%$ carbon and $4.7 \%$ oxygen.
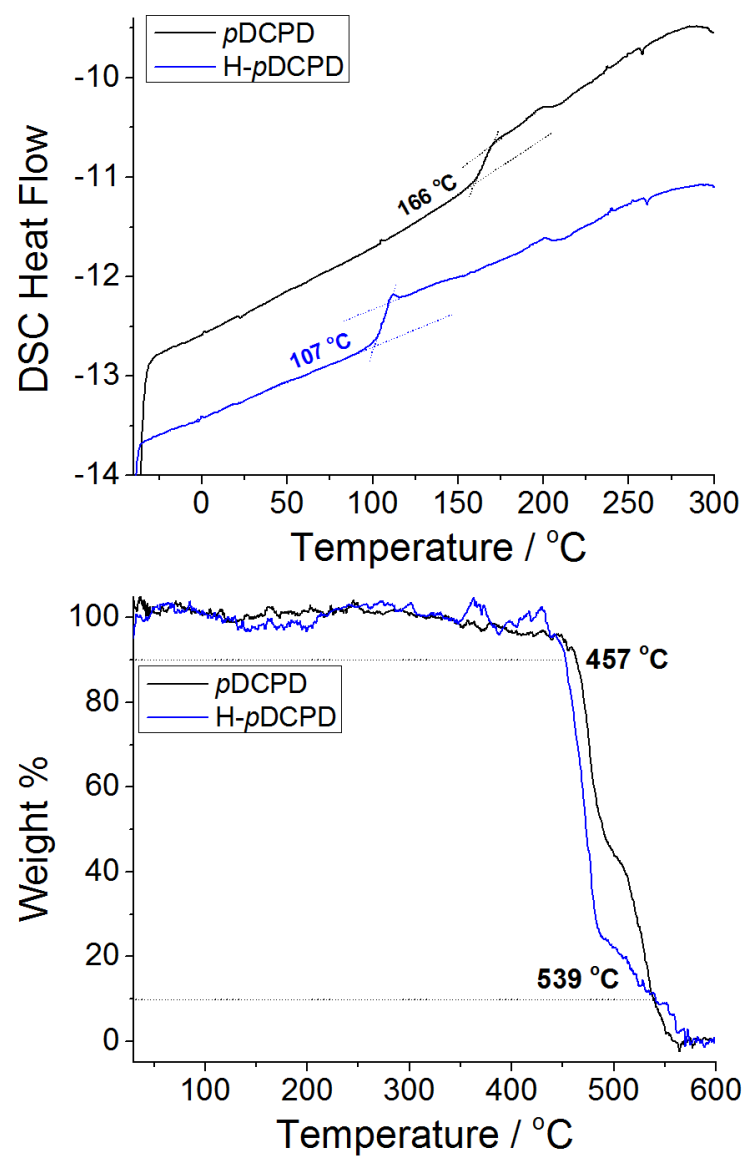

Figure 5. DSC (top) traces of 25- $p$ DCPD and 25-H- $p$ DCPD aerogels show a reduction in $T_{g}$ for the hydrogenated aerogel. TGA measurements show both 25-pDCPD and 25-H-pDCPD do not undergo significant weight loss until ca. $460{ }^{\circ} \mathrm{C}$.

While thermolysis of H- $p$ DCPD aerogels confirmed their oxidative stability, one interesting effect was a marked shrinkage of these aerogels as a result of the applied heat. For example, the measured density of 25-H- $p$ DCPD was found to be $710 \mathrm{mg}$ $\mathrm{mL}^{-1}$ after thermal treatment at $135{ }^{\circ} \mathrm{C}$ for 2 hours, a 14 -fold increase in aerogel density. By inspection, $p$ DCPD aerogels did not suffer such an extreme shrinkage, but the aerogel dimensions became too distorted after heating to reliably calculate a final density in these samples.

The loss in density upon heating is a direct result of the decrease in aerogel $\mathrm{T}_{\mathrm{g}}$ upon hydrogenation (Figure 5). Weighing the samples before and after thermolysis shows no change in mass, and TGA measurements (Figure 5) show that both $p$ DCPD and H- $p$ DCPD aerogels are stable to thermal weight loss to $>400{ }^{\circ} \mathrm{C}$. DSC measurements, on the other hand, show that the $\mathrm{T}_{\mathrm{g}}$ of $\mathrm{H}-p \mathrm{DCPD}$ aerogels decreases from $168 \pm 4{ }^{\circ} \mathrm{C}$ ( $p$ DCPD) to $111 \pm 3{ }^{\circ} \mathrm{C}$.

To probe this effect, $25-p$ DCPD and $25-\mathrm{H}-p$ DCPD aerogels were subjected to stepwise thermolysis with density determination after each thermal treatment (Figure 6). Heating these samples to $80{ }^{\circ} \mathrm{C}$ for 16 hours led to slight densification to 40 $\mathrm{mg} \mathrm{mL}^{-1}$ and $52 \mathrm{mg} \mathrm{mL}^{-1}$ respectively and additional heating to $100{ }^{\circ} \mathrm{C}$ for 8 hours was followed by additional shrinkage to $46 \mathrm{mg} \mathrm{mL}^{-1}$ and $89 \mathrm{mg} \mathrm{mL}^{-1}$. Complete 'shrinkage' of the 25 $\mathrm{H}-p \mathrm{DCPD}$ aerogel was realized after an additional heating to $135{ }^{\circ} \mathrm{C}$ for 4.5 hours. Here, the final density of $25-p$ DCPD aerogel was measured as $45 \mathrm{mg} \mathrm{mL}^{-1}$ while the density of 25 H- $p$ DCPD increased dramatically to $765 \mathrm{mg} \mathrm{mL}^{-1}$. Again, the $p$ DCPD aerogel discolored and its FTIR spectrum showed strong absorbances at $3400 \mathrm{~cm}^{-1}$ and $1700 \mathrm{~cm}^{-1}$ while the $\mathrm{H}-$ $p$ DCPD aerogel remained white in color and its FTIR spectrum remained virtually unchanged (see SI, Figure S24).

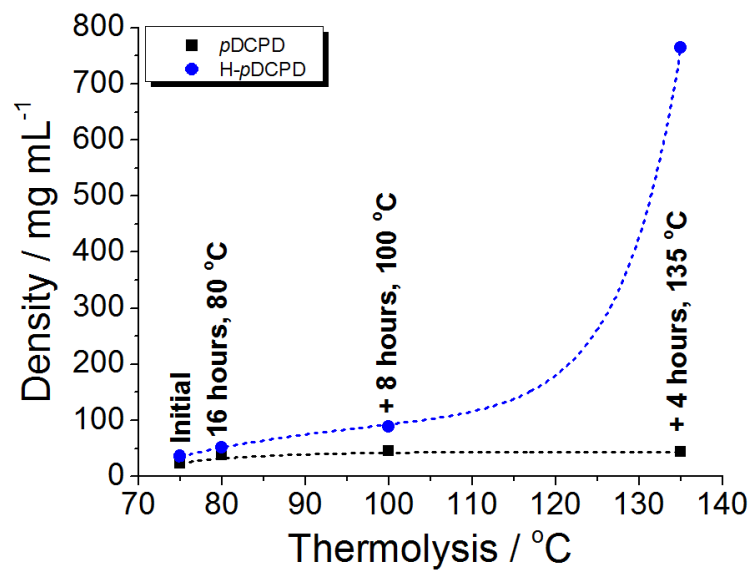

Figure 6. (Top) Evolution of the densities of 25- $p$ DCPD and 25$\mathrm{H}-p$ DCPD during stepwise thermolysis to a final temperature of $135{ }^{\circ} \mathrm{C}$. 25-H- $p$ DCPD shows an abrupt shrinkage when the thermolytic temperature goes above the $\mathrm{T}_{\mathrm{g}}$.

The hydrogenation of $p$ DCPD gels to form H- $p$ DCPD aerogels therefore significantly increases the oxidative stability of this system while suffering from a decrease in the materials' operating temperature. Characterization of these new aerogels' properties shows that while the fibrillar morphology remains constant, some deviation is observed in the measured pore volume, pore size and aerogel surface area that are consistent with the increase of shrinkage of H- $p$ DCPD during aerogel preparation. The inherently low cross-link density of $p$ DCPD aerogels may be responsible for the observance of $T_{g} s$ in these materials at $168{ }^{\circ} \mathrm{C}(p \mathrm{DCPD})$ and $111{ }^{\circ} \mathrm{C}(\mathrm{H}-p \mathrm{DCPD})$ and the ability of these materials to shrink at temperatures above $\mathrm{T}_{\mathrm{g}}$. The ease of preparation of these H- $p$ DCPD aerogels and their increased oxidative stability creates the need for synthesizing $p$ DCPD gels of increasing cross-link density prior to hydrogenation. We believe these materials may be less susceptible to shrinkage during supercritical drying and may increase the operating temperature for the hydrogenated system.

\section{ASSOCIATED CONTENT}

Supporting Information. Details of materials, experimental procedures, and methods of characterization. This material is available free of charge via the Internet at http://pubs.acs.org.

\section{AUTHOR INFORMATION}

\section{CORRESONDING AUTHOR}

*E-mail: lenhardt2@1lnl.gov

\section{AUTHOR CONTRIBUTIONS}

All authors have given approval to the final version of the manuscript. 


\section{FUNDING SOURCES}

This work was performed under the auspices of the U.S. Department of Energy by Lawrence Livermore National Laboratory under Contract DE-AC52-07NA27344. IM Release \# LLNLJRNL-564354.

\section{REFERENCES}

(1) Pekala, R. W. J. Mater. Sci. 1989, 24, 3221

(2) Gesser, H. D.; Goswami, P. C. Chem. Rev. 1989, 89, 765.

(3) Rolison, D. R.; Long, J. W.; Lytle, J. C.; Fischer, A. E.; Rhodes, C. P.; McEvoy, T. M.; Bourg, M. E.; Lubers, A. M. Chem. Soc. Rev. 2009, 38, 226.

(4) Pierre, A. C.; Pajonk, G. M. Chem. Rev. 2002, 102, 4243.

(5) Hüsing, N.; Schubert, U. Angew. Chem. Int. Ed. 1998, 37, 22.

(6) Yoldas, B. E.; Annen, M. J.; Bostaph, J. Chem. Mater. 2000, $12,2475$.

(7) Schmidt, M.; Schwertfeger, F. J. Non-Cryst. Solids 1998, 225, 364.

(8) Saliger, R.; Fischer, U.; Herta, C.; Fricke, J. J. Non-Cryst. Solids 1998, 225, 81.

(9) Kabbour, H.; Baumann, T. F.; Satcher, J. H.; Saulnier, A.; Ahn, C. C. Chem. Mater. 2006, 18, 6085.

(10) Kistler, S. S. Nature 1931, 127, 741.

(11) Gash, A. E.; Tillotson, T. M.; Satcher Jr, J. H.; Hrubesh, L. W.; Simpson, R. L. J. Non-Cryst. Solids 2001, 285, 22.
(12) Tillotson, T. M.; Sunderland, W. E.; Thomas, I. M.; Hrubesh, L. W. J. Sol-Gel Sci. Technol. 1994, 1, 241.

(13) Jin, H.; Nishiyama, Y.; Wada, M.; Kuga, S. Colloids and Surfaces A.: Physiochem. Eng. Aspects 2004, 240, 63.

(14) Rigacci, A.; Marechal, J. C.; Repoux, M.; Moreno, M.; Achard, P. J. Non-Cryst. Solids 2004, 350, 372.

(15) Lee, J.; Gould, G. J. Sol-Gel Sci. Technol. 2007, 44, 29.

(16) Perring, M.; Long, T. R.; Bowden, N. B. J. Mater. Sci. 2010, 20,8679.

(17) Yao, Z.; Zhou, L.-w.; Dai, B.-b.; Cao, K. J. Appl. Polym. Sci. 2012, 125, 2489.

(18) Hayano, S.; Takeyama, Y.; Tsunogae, Y.; Igarashi, I. Macromolecules 2006, 39, 4663.

(19) Yang, Y.-S.; Lafontaine, E.; Mortaigne, B. J. Appl. Polym. Sci. 1996, 60, 2419

(20) Hahn, S. F. J. Polym. Sci. A: Polym. Chem. 1992, 30, 397.

(21) Fernyhough, C. M.; Young, R. N.; Poche, D.; Degroot, A. W.; Bosscher, F. Macromolecules 2001, 34, 7034.

(22) Walker, R.; Conrad, R. M.; Grubbs, R. H. Macromolecules 2009, 42, 599.

(23) Abadie, M. J.; Dimonie, M.; Couve, C.; Dragutan, V. Eur. Polym. J. 2000, 36, 1213.

(24) Dawedeit, C.; Kim, S. H.; Braun, T.; Worsley, M. A.; Letts, S. A.; Wu, K. J.; Walton, C. C.; Chernov, A. A.; Satcher, J. H.; Hamza, A. V.; Biener, J. Soft Matter 2012, 8, 3518. 
Table of Contents Artwork:

Hydrogenation = Oxidative Stability

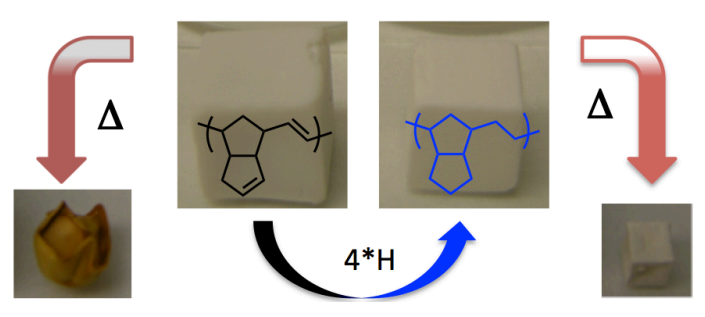

